positive for the antigen BT101, and using an actuarial method of analysis they calculated that $73 \%$ of patients with optic neuritis who were BT101 positive would develop multiple sclerosis within eight years compared with only $34^{\circ}$ of patients who were BT101 negative.

The problem remains that, despite a variety of claims to the contrary, ${ }^{8}{ }^{9}$ there is no reliable diagnostic test for multiple sclerosis. The diagnosis remains essentially clinical, based on the findings of dissemination of lesions in the central nervous system in both space and time. In a patient with apparently isolated optic neuritis any signs suggestive of more widespread lesions in the central nervous system must suggest multiple sclerosis, and in view of this perhaps all patients with optic neuritis should have a full neurological assessment. The techniques of auditory evoked responses ${ }^{10}$ and somatosensory evoked responses ${ }^{11}$ may be able to detect even preclinical disseminated lesions in either the brain stem or the spinal cord, and these may perhaps prove to be useful in the assessment of patients who appear to have isolated optic neuritis.

At present, however, our approach to a patient with isolated optic neuritis should be optimistic. The short-term prognosis is excellent and it is by no means certain that the patient will develop multiple sclerosis. The value of pursuing extensive complex and expensive investigations to give an exact prediction seems dubious. If the results of the tests are negative then the eventual outcome still remains uncertain. The fact that they are positive is of little practical help either to the physician or to the patient as, at present, there is no effective prophylaxis or treatment for multiple sclerosis.

1 Compston, D A S, et al, Brain, 1978, 101, 495.

2 Kurland, L T, et al, Acta Neurologica Scandinavica, 1966, 42, suppl 19, 157.

${ }^{3}$ Rischbieth, R H C, Proceedings of the Australian Association of Neurology, 1968, 5, 573.

${ }^{4}$ Bradley, W G, and Whitty, C W M, Fournal of Neurology, Neurosurgery, and Psychiatry, 1968, 31, 10.

${ }^{5}$ Hutchinson, W M, fournal of Neurology, Neurosurgery, and Psychiatry, 1976, 39, 283.

${ }^{6}$ McAlpine, D, Lumsden, C E, and Acheson, E F, Multiple Sclerosis. A Reappraisal. Edinburgh, Livingstone, 1965.

7 Thompson, E J, et al, British Medical fournal, 1979, 1, 16

${ }^{8}$ Field, E J, Shenton, B K, and Joyce, G, British Medical Fournal, 1974, $1,412$.

${ }^{9}$ Field, E J, Joyce, G, and Smith, B M, fournal of Neurology, 1977, 214, 113.

10 Robinson, K, and Rudge, P, Brain, 1977, 100, 19.

11 Small, D G, Matthews, W B, and Small, M, fournal of the Neurological Sciences, 1978, 35, 211.

\title{
Prevention of homicide
}

The medical profession has a long-standing interest in suicide and attempted suicide. Though few doctors these days are naive enough to believe that deliberate self-harm is an exclusively medical matter, equally few would deny that the study of the problem-and active intervention in appropriate cases-is a legitimate part of health care. Yet a related form of aggression, homicide and attempted homicide, is rarely considered in the same way. Casualty officers or general practitioners confronted with a patient threatening to murder his or her spouse, lover, or child are often at a loss as to what appropriate action they should take; sometimes they are even unsure how to determine whether the threat warrants medical (as opposed to other professional) attention.

A recent paper from Australia by Neville Parker ${ }^{1}$ highlights this anomaly by showing-as other studies $^{2-5}$ have shownthat many people who kill or try to kill are emotionally disturbed at the time. Parker estimated that about $10^{\circ}$, of the murderous assaults could have been prevented had the disturbed individuals had closer access to consultant psychiatric services, police forces, and other community agencies. How he arrived at this figure is not clear, but he quoted two vivid examples. The first was a woman whose husband was threatening to kill her; no one took any notice of her warnings and she was shot dead. The second, another woman, became (irrationally) convinced that her husband was a child killer and repeatedly told the police so. They did not intervene, and she shot him with his own rifle.

While the first man may or may not have been psychiatrically disturbed, the poor woman deserved more help than she received. The frequency and seriousness of incidents of this kind impressed itself on the recent British Parliamentary Select Committee on Violence in Marriage, ${ }^{6}$ which made several recommendations for changing the law to protect women in such circumstances. The Select Committee also proposed setting up 24-hour advisory services for women needing urgent help, so echoing the broader proposal made by the Butler Committee, which looked at the mentally abnormal offender ${ }^{7}$ and endorsed a BMA proposal for 24-hour multidisciplinary consultation and advisory services for patients with personality disorders.

A few organisations go some way to providing these facilities. The Inner London Probation and Aftercare Service has a special walk-in advisory service-but only on working daytime basis-and the Maudsley Hospital in South London provides a round-the-clock emergency clinic. One of the few set-ups aimed specifically at preventing homicide is the special violence clinic in Maryland, in the USA, organised by Lion and his colleagues, ${ }^{8}$ which invites those feeling violent and out of control to seek professional advice.

Unfortunately, we do not know how effective this type of clinic will prove, nor what are the links between psychiatric disorder (including psychosis) and violence. Nevertheless, mentally abnormal offenders, especially violent ones, present such problems to the psychiatric services in Britain at present that the Government has set aside funds for the provision of security units to contain them. Surely prevention should be given more priority. It must be at least as important to follow up the findings reported from Australia with more detailed studies and to set up experimental services such as that developed in Maryland. Only then can doctors evaluate the place for their skills and the extent to which their intervention can be effective.

${ }^{1}$ Parker, N, Medical fournal of Australia, 1979, 1, 36.

${ }^{2}$ Morris, N, and Hawkins, C, The Honest Politician's Guide to Crime Control. Chicago, University of Chicago Press, 1969.

${ }^{3}$ Wolfgang, M E, Patterns in Criminal Homicide. New York, Wiley, 1958.

${ }^{4}$ Gibson, E, and Klein, S, Murder 1957-68. London, HMSO, 1969.

${ }^{5}$ Morris, T, and Blom-Cooper, L A, A Calendar of Murder: Criminal Homicide in England Since 1957. London, Joseph, 1964.

${ }^{6}$ House of Commons, Parliamentary Papers, Report from the Select Committee on Violence in Marriage Volume 2. London, HMSO, 1975.

${ }^{7}$ Home Office, DHSS, Report of the Committee on Mentally Abnormal Offenders. London, HMSO, 1975.

${ }^{8}$ Lion, $\mathrm{J} \mathrm{R}$, in Violence and Victims, ed S A Pasternack, p 71. New York, Wiley, 1975. 